\title{
UMA ANÁLISE COMPARATIVA DE DIFERENTES EDIÇÕES DA REVISTA VEJA: O QUE MUDOU EM UM PERÍDO DE QUASE QUATRO DÉCADAS?
}

\section{A COMPARATIVE ANALYSIS OF DIFFERENT ISSUES OF VEJA MAGAZINE: WHAT HAS CHANGED IN A PERIOD OF NEARLY FOUR DECADES?}

\section{Fernanda Taís Brignol Guimarães}

\author{
Mestranda em Linguística Aplicada pelo Universidade Católica de Pelotas (UCPEL) \\ Bolsista CAPES. \\ E-mail: fernandabage@hotmail.com

\section{Vinícius Oliveira de Oliveira} \\ Mestrando em Linguística Aplicada pela Universidade Católica de Pelotas (UCPEL) \\ Bolsista CNPq \\ E-mail: viniciusdeoliveira91@gmail.com

\section{Cristiani Martins de Souza} \\ Graduação em Letras pela Universidade Federal do Pampa (UNIPAMPA) \\ E-mail: cristianimartinssouza@gmail.com
}

\section{RESUMO}

Analisamos, neste artigo, duas edições da Revista Veja, publicadas em diferentes épocas, uma de 1974 e outra de 2012, com o objetivo de estabelecer uma relação comparativa entre ambas. Com base no estudo de Hernandes (2006), intitulado O jornalismo impresso, pretendemos identificar o que mudou nessa revista, através da comparação de duas de suas edições, publicadas com uma distância de quase quatro décadas entre uma edição e outra. Como resultados, apontamos que, embora a Veja tenha preservado certa linearidade em seus padrões de design, ao longo desse tempo os assuntos abordados não são mais os mesmos. A mudança de assuntos essencialmente ligados à economia e à política, presentes na edição de 1974, para assuntos ligados a temas mais leves como a vida das celebridades, por exemplo, edição de 2012 , se justifica pelo objetivo de alcançar o público consumidor de maneira mais rentável.

Palavras-chave: Revista Veja. Estratégias da mídia. Análise comparativa.

\begin{abstract}
We analyze in this article two editions of Veja magazine, published at different times, one 1974 and one 2012, with the goal of establishing a comparative relationship between them. Based on the study of Hernandes (2006), entitled The print journalism, we intend to identify what has
\end{abstract}


changed in this magazine, by comparing two of its editions, published with a distance of nearly four decades between the two editions. As a result, we point out that while Veja has preserved certain linearity in its design patterns, over that time the topics discussed are not the same. The changes essentially related to the economy and politics themes, presented in the edition 1974, opposed on themes relating to lighter topics such as the lives of celebrities, for example, in 2012 edition, is justified by the objective of reaching the consuming public so more profitable.

Keywords: Veja Magazine. Media strategies. Comparative analysis.

\section{INTRODUÇÃO}

Os meios de comunicação impressos, ou mídias impressas, como os jornais e as revistas, por exemplo, se destinam a um público bem diferente daquele ligado aos meios de comunicação de massa, como é o caso da televisão. Isso se reflete, principalmente, na escolha dos temas abordados nas matérias dessas diferentes mídias. Nas palavras de Hernandes, em seu texto intitulado O jornalismo impresso: "Proprietários de jornais e revistas afirmam que seus produtos são para a 'elite', os chamados formadores de opinião (HERNANDES, 2006, p. 183 [grifos no original])". Dessa forma, existem "certas expectativas e exigências em termos intelectuais" por parte dos consumidores desse tipo de produto. O que acaba gerando uma distinção entre esse público e o público ligado aos veículos de informação de massa.

Porém, ao longo dos tempos, esses conceitos vêm mudando significativamente. Aos poucos, conforme citação de Marcelo Beraba (ombudsman da Folha de São Paulo), presente no texto de Hernandes (2006, p. 185), “as revistas (...) foram trocando o noticiário pesado dos assuntos públicos, como a política e a economia, por seções mais leves e temas relativos à vida das pessoas, como saúde, finanças, crenças, comportamento". Nessa nova abordagem, "as celebridades têm espaço valorizado". Essa mudança está fundamentada, na maioria das vezes, em estratégias e objetivos comerciais, pois, dessa forma, a revista passa a abranger um maior público-consumidor, elevando, assim, seu percentual de vendas.

Além da questão dos temas abordados, há que se considerar, também, a forma de apresentação das matérias veiculadas nas mídias impressas, que contam com estratégias como o uso e a disposição de imagens na página, tamanho e cor da letra, recursos de destaque como o negrito, geralmente, utilizados nos títulos, recursos esses que se mostram como exemplos de escolhas cuidadosas, pensadas de acordo com o tipo de leitor que se quer atingir, bem como com o grau de envolvimento desse leitor para com o jornal ou revista em questão. 
Dito de outra forma, o simples recurso de utilização de uma imagem, por exemplo, pode ser feito de forma exagerada, sensacionalista, com o objetivo de causar espanto, indignação, curiosidade, sofrimento etc., entre os leitores. A exemplo disso, temos o caso de reportagens sobre acidentes, em que as imagens das vítimas são colocadas em destaque, ou então, imagens de cenas íntimas da vida de celebridades, que são usadas como uma estratégia para aguçar a curiosidade das pessoas quanto à leitura da matéria. Dessa forma, uma revista que apresenta sempre imagens instigantes, mesmo que sensacionalista, acaba criando um vínculo de fidelização com o leitor, a partir da sensibilidade que despertada em seu público, mobilizando-o, assim, a manter um relacionamento de longo prazo com tal veículo de comunicação.

Diante do que foi exposto, pretendemos, neste artigo, atentar para as mudanças que vêm ocorrendo, principalmente, no que diz respeito às revistas. Para tanto, analisamos duas edições da revista Veja, publicadas em diferentes décadas: uma de 1974 e outra de 2012, como forma de estabelecer uma relação comparativa entre ambas as edições. Com base no estudo de Hernandes (2006), intitulado $O$ jornalismo impresso, pretendemos identificar o que mudou nessa revista, através da comparação realizada dessas duas edições publicadas com uma distância de quase quatro décadas entre uma edição e outra.

Na próxima seção, apresentamos o referencial teórico que embasa o presente estudo, partindo, a seguir, para as seções que apresentam a metodologia, análise dos dados, considerações finais e, por fim, as referências bibliográficas.

\section{REFERENCIAL TEÓRICO}

Em seu estudo sobre as mídias impressas, intitulado $O$ jornalismo impresso, Hernandes (2006), analisa como ponto de partida, as especificidades e o funcionamento de determinados elementos mobilizados nessas mídias, os quais têm o objetivo de gerenciar a atenção do público-consumidor. A esse respeito, o autor destaca, como "efeitos do projeto gráfico e da diagramação (...), as estratégias de arrebatamento, sustentação e fidelização da atenção dos leitores" (p. 185).

Conforme definição de Hernandes (2006, p. 187 [grifos no original]), temos:

Estratégia de arrebatamento - As iscas estão relacionadas à criação de descontinuidades do plano de expressão com a função obter o primeiro engajamento perceptivo do leitor. São, portanto, estratégias de ordem sensível.

Estratégia de sustentação - Há aqui uma mobilização mais passional do leitor. Ele é persuadido, inicialmente, pela forma de apresentação do jornal, de que pode se informar de maneira rápida e eficiente. Jornais e revistas apresentam-se como um tipo 
de objeto prático, necessário, bonito, "indispensável" ou que "não dá pra não ler". (Vale lembrar ainda que a "passionalização" do leitor é função principalmente dos conteúdos. Ou seja, é preciso leitura, passagem do sensível par o inteligível. Nesse sentido, a função da diagramação é a de permitir que a importância desses conteúdos se torne visualmente evidente e chamativa por meio da ocupação espacial. O espaço é manipulado para se obter maior ou menor nível de atenção e a correspondente tensão do leitor).

Estratégia de fidelização - Nasce do contato rotineiro com diferentes edições e da satisfação de saber obter o que se quer com facilidade. Pressupõe contatos anteriores bem-sucedidos. Essa familiaridade com relação ao suporte gráfico-plástico é produto do uso contínuo das mesmas famílias de letras, certos modos de ocupação de espaços e divisões, maneiras rotineiras de valorizar ou desvalorizar conteúdos que criam um código comum entre enunciador e enunciatário.

Quanto à estratégia do plano de expressão, Hernandes (2006, p. 191 [grifos no original]) apresenta a definição de quatro leis, as quais são descritas a seguir:

Primeira lei: o valor de uma unidade noticiosa é proporcional ao espaço a ela concedido. Dar mais espaço valoriza. Dar menos espaço desvaloriza. A lei também vale para os elementos. Por exemplo, se as fotos ocupam mais espaço, somos comunicados de que as imagens estão sendo mais valorizadas.

Segunda lei: tudo o que estiver na parte de cima tem mais valor do que na parte de baixo. A lei é validade tanto para a relação entre unidades noticiosas numa mesma página (ou conjunto de páginas) quanto para elementos de uma única unidade noticiosa. Nos diários, há raros casos em que há um bloco maior no meio da página do que em cima. Nessa situação, a primeira lei prevalece.

Terceira lei: a máxima valorização espacial de uma revista ou diário acontece na capa ou na primeira página. Nesse espaço, o enunciador informa o assunto ou assuntos que considera mais importantes na edição.

Quarta lei: o início de uma unidade noticiosa é o espaço mais valorizado. Essa lei leva à colocação das principais informações e dos elementos de mais impacto sempre no começo.

Quanto à distribuição das seções, bem como a divisão de conteúdos por seções nos jornais e revistas, o autor destaca a existência de quatro tipos de sujeitos a serem observados: sujeito político, sujeito lúdico, sujeito pragmático e sujeito harmonizador, sendo que o surgimento desses dois últimos ocorreu devido às segmentações atuais desses suportes. Segundo Hernandes (2006, p. 200), “A segmentação das notícias em editoriais, cadernos, suplementos tem profundas implicações na construção do leitor das publicações (...)”.

A seguir vejamos as definições de Hernandes (2006, p. 201 [grifos no original]) para cada tipo de sujeito por ele elencado:

Sujeito político, interessado em temas da coletividade. (...) "A editoria se dedica à vida política, institucional e aos movimentos sociais. Procura oferecer ao leitor informações pluralistas e apartidárias, para que ele exerça sua cidadania."

Sujeito lúdico, que se importa com atividades que lhe dão prazer, como futebol, os quadrinhos, a peça bem cotada em cartaz (...). 
Sujeito pragmático - Ao contrário do sujeito político, que quer ter uma visão da coletividade e de seu papel nela, o pragmático espera encontrar no jornal soluções rápidas para seus problemas práticos. [como, por exemplo,] “(...) informações úteis ao seu dia-a-dia nas áreas de segurança, educação e direito do consumidor”; (...) [informações do tipo:] como aplicar bem os recursos; (...) a melhor e mais vantajosa viagem, (...) como abrir e gerir uma empresa, entre outros exemplos.

Sujeito harmonizador - é o que está interessado em "qualidade de vida", ou seja, meios de se ter mais saúde, de buscar equilíbrio, de viver relações mais satisfatórias. Ele pode ser tanto científico, ligado às descobertas de novos remédios e tratamentos médicos, por exemplo, como místico, que percebe a vida regida por forças divinas, dos planetas, da natureza.

Sobre a organização estrutural das mídias impressas, Hernandes (2006, p. 207) afirma que "o verbal se dá a conhecer a partir de um suporte visual que tem uma significação claramente determinada nos projetos gráficos”, pois visa causar impacto na página. Portanto, para causar esse impacto desejado utiliza-se de grandes conjuntos significantes. Vejamos, a seguir, a definição do autor (p. 207-208 [grifos no original]) com relação aos cinco conjuntos de significantes manejados pela diagramação:

Verbal, manifestado tipograficamente - diz respeito às letras, aos tipos gráficos e às suas possibilidades de concretização, como cores, texturas, tamanhos que geram títulos, matérias, legendas.

Fotográfico - inclui imagens fotográficas obtidas por meios convencionais ou digitais.

Pictórico - abrange produtos de arte e de técnica de representar, numa superfície, formas que vão do figurativo ao abstrato. Inclui charges, ilustrações, quadrinhos, vinhetas, além de produções digitais que criam, inclusive, efeitos de terceira dimensão.

Misto - infográficos, fusões que representam um todo de sentido com base na utilização dos outros conjuntos significantes citados.

A diagramação também utiliza certos elementos com funções específicas, que estamos chamando de:

Diagramáticos - linhas, fundos, caixas coloridas ou vazadas. A maioria desses recursos tem como função auxiliar na organização visual e não remete a conteúdos.

Com relação aos recursos de fotografia, ou o fotojornalismo, o autor argumenta que os fotógrafos estão sempre na busca da “"grande foto', que significa mais atenção, mais leitores e mais vendas". O autor afirma que "uma fotografia deve ser uma das principais iscas para o olhar em uma página, ou seja, uma das mais importantes armas na estratégia de arrebatamento e de sustentação". Para Hernandes, outro motivo que faz com que a fotografia seja tão explorada nas revistas é o fato de que ela serve de prova para mostrar a realidade, tornando-a, dessa forma, inquestionável. Conforme o autor "O fotojornalismo valoriza o flagrante" (p. 2017), quanto a isso, Hernandes (2006, p. 214) diz que: “É preciso um fotógrafo estar presente na hora do 
acontecimento, (...). O tsunami que varreu a Ásia (...) foi (...) pouco fotografado. Perdido o momento de ápice narrativo, só se registram consequências. A fotografia tem ainda que dizer muito com apenas um enquadramento".

Hernandes destaca, ainda, a mobilização de quatro tipos de estratégias no que diz respeito à utilização de diferentes tipos de fotos pelas mídias impressas, como o jornal e a revista, que são as seguintes: fotos de registro, fotos de síntese, foto de flagrante e foto plástica. Segue a definição do autor para cada uma delas (pp. 218-221 [grifos no original]):

Foto de registro - (...) São as fotos mais comuns encontradas na mídia impressa. A foto de registro é a que mais se aproxima do papal "ancorador" da fotografia nos textos: serve para mostrar o deputado de quem se fala na parte escrita da matéria ou o jogador que fez determinado gol, ou ainda como ficou o carro destruído em um acidente. É utilizada ainda para "decorar" a página, buscar o olhar do leitor. Tem grande valor na estratégia de fazer crer na objetividade da informação. É de fácil decodificação (...).

Foto de síntese - (...) é a mais adequada para representar o que é a "força expressiva" do assunto abordado. Resume toda uma situação tratada na parte escrita da matéria e geralmente apela para a passionalidade do observador (estratégia de sustentação). (...) Fica evidente para o leitor que a realidade não está sendo mais mostrada de maneira "objetiva", mas filtrada por um conjunto de valores que quer ressaltar determinados simbolismos. Essa foto é uma sinédoque visual (um tipo de metonímia em que uma parte representa o todo). (...) A composição da fotografia também impressiona (...).

Foto de flagrante - capta o chamado "instante decisivo" (...) e tem enorme valor documental e impactante. Acreditamos que o ato do fotógrafo de captar um acontecimento no momento de maior tensão narrativa é a essência do fotojornalismo. (...) ilustra muito bem o potencial de atenção, curiosidade e tensão que o enunciador (...) [quer] despertar no enunciatário (...).

Foto plástica - Busca efeito estético (...) e, dessa maneira, é a que mais expõe o fotógrafo como enunciador. Há um forte sentido de "autoria" da foto, de um ponto de vista subjetivo. Vale notar que a busca por uma representação mais estilizada, não raras vezes, determina a perda de parte da iconicidade, da representação do real. $\mathrm{O}$ leitor é convidado a uma interpretação mais pausada, elaborada. (...) O caráter pictórico da imagem é evidente, com um sofisticado uso da luz e das sombras para apresentar formas de maneira muito econômica e produzir efeitos dramáticos, notadamente o de conduzir o olhar [do observador] (...).

\section{METODOLOGIA}

Para a presente análise serão utilizadas duas edições da Revista Veja como um meio de estabelecer uma relação comparativa entre ambas, sendo elas, a edição 283, publicada em 6 de fevereiro de 1974, e a edição 2253, publicada em 25 de janeiro de 2012. A escolha por edições de épocas diferentes se dá pelo objetivo de identificarmos e percebermos o que mudou nessa revista durante esse período, de quase quatro décadas entre uma edição e outra. A análise contemplará desde a organização textual, estratégias de expressão, tipos de fontes utilizadas, diagramação até imagens e capas apresentadas. 


\section{ANÁLISE DOS DADOS}

Partindo para a análise das duas edições da revista Veja, supracitadas, percebemos, a respeito das principais reportagens do exemplar ou notícias de capa, que a edição de 1974 apresenta uma tragédia ocorrida em São Paulo, trata-se de um incêndio ocorrido em um prédio da cidade. A foto do prédio em chamas, escolhida para ilustrar a capa da revista, toma conta de todo o espaço, chamando atenção de todos para o fato. Enquanto que a edição de 2012 traz, como notícia principal, a polêmica sobre cenas de sexo explícito ocorrido no Big Brother Brasil 12, reality show exibido pela Rede Globo de Televisão, em que a capa é composta pela imagem de um corpo feminino em trajes de banho, fotografado de costas. Essa imagem possui dimensões proporcionais a quase todo o espaço destinado para a capa da revista, deixando apenas espaços bem pequenos para mais duas chamadas - uma sobre o Crack e outra sobre a cidade de São Paulo. Comparando as duas capas, conseguimos perceber claramente o que nos coloca Hernandes (2006), quando fala sobre a mudança das revistas quanto à escolha de seus temas ao longo dos tempos.

Embora, na edição mais antiga, seja possível perceber que a capa apresenta um tom apelativo, principalmente na escolha da foto, que por ser chocante acaba atraindo a atenção do leitor para a notícia. Essa edição trata de uma tragédia, ou seja, um assunto tratado com seriedade. Já na edição de 2012, a capa aborda uma polêmica sobre o reality show da Globo, em que , como estratégia para atrair a atenção de um maior número de leitores, a Veja apela para uma notícia que interessaria a um público menos exigente em termos intelectuais. Dessa forma, a revista acaba abrangendo o mesmo público ligado a veículos de informação de massa, a partir do momento em que opta por explorar temas sem a menor relevância social, mas que geram a curiosidade de um número significativo de leitores.

Quanto à organização interna dos dois exemplares da revista Veja analisados, percebemos que a edição de 1974 traz a notícia principal logo na página 14, após entrevista em páginas amareladas - sobre o futuro da telefonia, algumas propagandas de cigarro e de carro, o espaço "Cartas" - em que o leitor pode expor sua opinião sobre os mais variados temas, a página humorística de Millôr Fernandes e a seção Carta ao leitor.

O desenvolvimento da notícia principal - que retrata o incêndio ocorrido em um prédio na cidade de São Paulo - apresenta fotos ainda mais apelativas que a escolhida para compor a capa da revista. As fotos mostram o drama vivido pelas vítimas, em que é possível perceber cenas de pessoas mortas, carbonizadas, no meio da rua ou ainda no prédio, outras se jogando dos últimos andares direto para o solo, a fim de escaparem do fogo e outras, ainda, desesperadas esperando socorro em meio às chamas que tomam conta de todo o prédio. 
Essa reportagem vai da pg. 14 até a pg. 30, são 17 páginas destinadas à cobertura completa da tragédia e recheadas de imagens chocantes. A primeira página da reportagem traz o título bem destacado através da utilização de uma fonte de letra bem maior do que o da utilizada no texto. Além disso, a página está dividida entre imagem na parte superior e texto logo abaixo. No final da primeira página, após o texto, encontramos uma frase - com uma fonte um pouco menor que a do título - indicando que nas próximas páginas o leitor encontrará imagens do maior incêndio de São Paulo. As páginas que seguem são compostas de imagens dispostas em quase todo o espaço da página, com uma pequena legenda indicando do que se trata. Apenas a partir da página 27 voltamos a encontrar texto em maior proporção do que as imagens apresentadas.

Após a reportagem principal, encontramos uma reportagem sobre o palácio do planalto, logo após, a seção intitulada Diplomacia, Seção Política, Internacional, Ciência, Educação, Comportamento, Televisão, Cidades, Gente, Datas, Economia e Negócios, Teatro, Música, Literatura, Arte, Investimentos - em páginas amareladas - e, por fim, a seção Cotações. Já na edição de 2012, a reportagem principal, que trata da polêmica envolvendo o reality show da Globo, ocupa o espaço que vai da pg. 84 até a pg. 91, estendendo-se pelas 08 páginas que compõem a seção intitulada Especial. O título da notícia “A casa caiu”, está localizado na parte superior da segunda página da reportagem, em letras bem destacadas pelo tamanho da fonte e por estarem em negrito. Logo abaixo do título encontramos uma pequena chamada, em letras um pouco menores, indicando o teor da notícia. Após essa chamada está o texto que explora o fato.

A primeira página é composta de pequenas imagens, posicionadas à esquerda, em que aparecem trocas de beijos e carícias entre os participantes do programa. À direita, nessa mesma página, temos uma imagem que ocupa quase todo o espaço e vai até a segunda página. Tratase de uma foto em que aparecem três meninas de biquíni, dançando. As próximas páginas são compostas de alternância entre texto e imagens. Ora as imagens aparecem na parte superior da página, ora no meio, misturando-se com o texto.

Antes da seção que apresenta a notícia sobre a polêmica envolvendo o Big Brother Brasil 12, a organização da revista se dá da seguinte forma: as seis primeiras páginas estão destinadas a propagandas, entre elas, do Banco Itaú e da Caixa. Nas páginas 08 e 09 encontramos um índice com fotos ilustrativas. Logo após, temos os espaços Carta ao leitor que também aborda o tema polêmico presente na capa da revista - e Entrevistas. Em seguida, temos pequenas reportagens intercaladas com algumas propagandas, seção Leitor, Panorama, 
Panorama Datas, Panorama Holofote, Panorama Sobe Desce - Conversa - Números, Panorama Radar, Panorama Veja Essa, Brasil, Internacional, Economia, Gente, e a seção Especial - que traz a reportagem principal da edição.

Após a seção que aborda a notícia de capa da edição, encontramos a seção cidades, uma indicação de filme, a seção Tecnologia, Beleza, Carnaval, Guia Veja, Artes e Espetáculos, Cinema, Livros, Veja Recomenda e, para finalizar, temos um ensaio de Roberto Pompeu de Toledo.

É importante ressaltar que se torna perceptível a valorização atribuída à reportagem de capa da edição 2012 da Veja, pelo fato de que o tema, além de ser escolhido para compor a capa da revista, integra, ainda, o conteúdo abordado no espaço Carta ao leitor.

Quanto à organização textual das duas edições, percebemos que há a presença de estratégias utilizadas para captar e manter a atenção do leitor. Como estratégias de arrebatamento, em que há a preocupação em se criar "iscas" para atrair de forma impactante a atenção do leitor, podemos citar o uso das imagens, que chamam a atenção tanto pelo espaço que ocupam na página quanto pelo contraste de cores - imagens bem coloridas, chamativas contrastando com fundos totalmente brancos, como é o caso da edição de 2012 ou, então, na edição de 1974 o uso de fundos escuros, imagem fechada, com efeitos de sombra a fim de passar para o leitor um aspecto fúnebre. $\mathrm{O}$ tamanho da letra e a fonte utilizada também servem com iscas para o olhar, dando ênfase para o que será abordado no texto e, dessa forma, atraindo a atenção do leitor para a notícia.

Como estratégias de sustentação, encontramos, nas edições de 1974 e de 2012, pequenas partes destacadas do texto, a fim de resumir o que está sendo tratado e dar ao leitor a impressão de uma fácil legibilidade, em que ele encontrará o que é mais importante com facilidade e conseguirá ter acesso rápido ao que lhe interessa de fato. Outra estratégia de sustentação encontrada nessas edições é o fato de que através da organização espacial das reportagens, torna-se possível que o leitor perceba a importância e a valorização que a revista atribuiu para a notícia apresentada. Através da ocupação de grande espaço, com imagens e cores chamativas aos olhos do público, como é o caso das reportagens analisadas, é possível que se obtenha o engajamento do leitor por perceber que se deu evidência ao fato noticiado. Além disso, percebemos, nessas edições, a busca pela produção de publicações com um layout rico, pois são atraentes, bonitas, completas, atendendo, assim, a mais uma das estratégias de sustentação, que alia beleza ao caráter prático exigido pelo leitor. 
Já como estratégias de fidelização, é possível perceber uma repetição de determinados padrões. Embora de 1974 até 2012, a estrutura da revista e disposição das seções tenha mudado um pouco, é possível se obter uma identificação em que o leitor consiga saber onde buscar a informação que deseja pela familiaridade com a organização da revista.

Pensando na primeira lei das estratégias do plano de expressão, notamos que, na edição de 1974, há uma maior valorização da imagem do que do texto. A capa da revista dá espaço a uma única imagem, o prédio em chamas, que ocupa toda a área, dividindo o espaço apenas com o logo da revista e com uma pequena chamada sobre a reportagem no canto superior esquerdo "Fogo e morte outra vez". No interior da revista, a reportagem também é composta por mais imagens em relação ao texto. Em várias páginas encontramos a área totalmente ocupada por fotos apenas com uma pequena legenda. Somente na primeira página da reportagem e nas últimas é que encontramos a alternância entre texto e imagem, em alguns momentos texto em maior proporção. Assim percebemos, nessa reportagem, uma maior valorização da imagem como forma de obter a atenção do leitor - maior área ocupada x menor área ocupada.

$2^{\mathbf{a}}$ lei - parte de cima $\mathbf{x}$ parte de baixo: Também com relação à segunda lei, temos a valorização da imagem, na edição antiga, pois, já na primeira página da reportagem encontramos imagens na parte superior seguida de texto logo abaixo.

Ainda para a $3^{\mathrm{a}}$ lei (exterior $\mathbf{x}$ interior) e para a $4^{\mathrm{a}}$ lei (inicial $\mathbf{x}$ final): A edição da Veja de 74 segue a lógica da valorização da imagem. Isso é facilmente explicado pela forma como foi feito o uso da imagem na capa (exterior), em que há uma grande exploração da foto do prédio em chamas. E, para a quarta lei (inicial x final), percebemos que, já na primeira página da notícia, é a imagem que dá inicio a unidade noticiosa, o que explica uma maior valorização desta diante do texto. Logo após encontramos várias páginas compostas totalmente por imagens e, apenas nas páginas finais da reportagem é que nos deparamos com o texto novamente.

Se formos aplicar essas quatro leis na análise da edição mais recente, ou seja, a edição de 2012, percebemos que há uma recorrência na valorização da imagem. Pois, assim como na edição antiga, a de 2012 também explora a imagem na composição da capa ( $1^{\mathrm{a}}$ lei - maior área ocupada x menor área ocupada), só que desta vez, existem duas pequenas chamadas para outras reportagens que dividem espaço com a reportagem principal da edição. As primeiras páginas da notícia também iniciam com as imagens disposta na parte superior seguidas de texto logo abaixo ( $2^{\mathrm{a}}$ lei - parte de cima x parte de baixo). A capa e as primeiras páginas da notícia também exploram a imagem como forma de obter a atenção do leitor para a reportagem ( $3^{\mathrm{a}}$ lei - exterior $\mathrm{x}$ interior). E, por fim, é a imagem que dá início à unidade noticiosa ( $4^{\mathrm{a}}$ lei - inicial $\mathrm{x}$ final). 
Dessa forma, foi possível notar que houve uma recorrência da valorização da imagem nas duas edições da revista Veja analisadas. Em que, aplicadas as quatro leis relativas à estratégia do plano de expressão para a análise das duas edições, obtivemos a confirmação de que a imagem foi utilizada a fim de se obter um maior potencial de atenção do leitor para a reportagem.

Outra questão relevante levantada na análise das duas edições da revista é o fato de que tanto para a edição antiga quanto para a recente, a reportagem de capa dá atenção a uma notícia quente, ou seja, o tipo de notícia do momento, que apresenta prazo de validade para obter a atenção do leitor e gerar impacto/efeitos de sentido desejado sobre o público-alvo.

A revista Veja apresenta, também, nas duas edições analisadas, uma recorrente preocupação com os quatro tipos de sujeito apresentados por Hernandes (2006): sujeito político, sujeito lúdico, sujeito pragmático e sujeito harmonizador, com exceção deste último que é contemplado somente na edição recente.

Tanto na edição antiga como na recente, encontramos seções que tratam de temas da coletividade (sujeito político): Política, Brasil, Exterior, Internacional, Ciência, Educação etc; Seções que tratam de atividades que dão prazer ao leitor (sujeito lúdico): Cinema, Artes, Teatro, Música etc; Seções que tratam de soluções de problemas individuais, para àquele leitor que procura formas rápidas de solucionar seus problemas (sujeito pragmático): Investimentos, Economia e Negócios, Tecnologia etc; E, por fim, somente na edição de 2012, como já foi dito, encontramos seções que tratam da qualidade de vida, que abordam meios de se obter saúde (sujeito harmonizador): Guia Veja - que, na edição 2012, aborda o tema ligado a importância das frutas como forma de boa alimentação - e a seção Leitor - que, também na edição 2012 aborda temas como a prevenção contra a Dengue e, também, sobre exercícios físicos.

Quanto à estrutura das duas edições da Veja, ora analisadas, notamos que a edição de 1974 contém um caráter de maior seriedade e aborda mais temas densos que a de 2012. A edição mais antiga está destinada a um público seleto, intelectual, elitizado. Enquanto que a edição de 2012 apresenta um caráter mais despojado, maior abertura e liberdade na escolha dos temas abordados e possui uma inclinação muito clara à direita política. Apresenta mais temas leves e abrange um maior público, ou seja, um público com menos exigências em termos intelectuais, àquele ligado a meios de informação de massa, como por exemplo, a televisão.

Além disso, notamos que a edição de 1974 traz como notícia de capa um tema denso (a tragédia ocorrida em São Paulo), enquanto que a de 2012 apresenta na capa um tema leve (a polêmica do BBB). A revista de 1974 inicia com temas leves, passa a tratar de temas densos e 
termina com temas leves. Dessa forma, segue a lógica de Chauí, quando diz, em seu capítulo intitulado Simulacro e Poder: Uma Análise da Mídia, que a estrutura dos noticiários age de maneira a produzir o sentimento de bem-estar no espectador, indicando que o mundo tem problemas, mas apesar dos pesares, ele vai bem, obrigado (CHAUÍ, 2006). Também, na edição de 2012, notamos que há presença inicial de temas leves, porém há pouca abordagem de temas densos e a finalização retoma novamente temas leves.

Há recorrência quanto à organização estrutural das duas edições da Veja aqui analisadas, porém, na edição antiga, notamos uma maior ênfase a temas densos do que na edição recente. Fato este que confirma o que foi tratado anteriormente sobre o que nos apresenta Hernandes (2006), em seu texto intitulado $\mathrm{O}$ jornalismo impresso, em que o autor fala a respeito da mudança das revistas ao longo dos tempos, afirmando que as revistas antigas tratavam de temas mais densos e que as recentes tratam de temas mais leves, relativos à vida das pessoas.

Com relação à organização estrutural das mídias impressas, vejamos quais dos cinco conjuntos de significantes manejados pela diagramação, descritos por Hernandes (2006), estão presentes nas edições da revista Veja, por nós analisada.

Verbal, manifestado tipograficamente - Enquanto que na edição de 1974, a revista apresenta uma letra mais sóbria, dando destaque aos assuntos apenas utilizando-a em negrito, a edição de 2012, possui letras diferenciadas e bem mais atrativas, despertando assim, um maior interesse dos leitores. Além disso, na edição mais antiga há a ausência de cores, estando as letras, em sua grande maioria, pretas, e algumas poucas vezes em branco. Já na edição mais atual da revista, além das letras possuírem diversas formas e tamanhos, apresentam, ainda, uma grande variedade de cores.

Fotográfico - Ambas as revistas possuem um grande número de imagens fotográficas, mas novamente as cores se sobressaem na edição mais atual, ambas não somente utilizam as imagens como um reforço e reafirmação ao texto, como também possuem muitas imagens publicitárias e que visam vender produtos, sendo que, as imagens da revista de 2012 são bem mais atrativas.

Pictórico - A edição de 1974 não apresenta diferentes técnicas de representação, nem formas figurativas ou abstratas, enquanto a edição de 2012 possui diversas técnicas e formas figurativas como, por exemplo, as que encontramos nas páginas 11 e 14 . O elemento pictórico pode ser representações feitas à mão, via computador, ou essencialmente digitais para representar figuras e situações, geralmente com o uso abundante da cor, o que fica evidente na página 95 com um desenho que representa uma mulher. 
Misto - Este é o item onde há uma fusão dos outros três citados acima, conforme mostram as páginas 42, 43 e 74 e 75 da edição de 2012, em que há presença de diferentes tipos de letras, imagens, e, ainda representações digitais. Em relação aos elementos mistos, segundo o autor, os infográficos são os que têm ganhado espaço crescente na mídia impressa. Tal infografia pode ser percebida nas páginas 94 e 95 da mesma edição, em que há a combinação de desenhos, fotos e gráficos com o objetivo de apoiar e reafirmar a ideia que é dada pelo texto.

Além dos elementos citados, a diagramação de uma revista também pode utilizar linhas, fundos, caixas coloridas ou vazadas com o objetivo de auxiliar na organização visual, algo que está bastante presente na edição de 2012 que organiza seu espaço através de diversas caixas de textos ou fragmentos como pode ser percebido na página 83 , o que dá ao leitor uma melhor percepção e localização das diferentes matérias e assuntos que ali estão sendo tratados, diferentemente do que acontece da edição de 1974, em que os textos e matérias são apresentadas, em sua maioria, apenas em colunas, tornando-as mais densas e cansativas.

Como já citado anteriormente, o tipo gráfico e a fonte da letra utilizada podem causar diferentes impressões aos leitores, sendo assim, uma estratégia bastante pensada pelos editores de revistas e jornais com o objetivo de significar "algo mais". Partindo desse princípio podemos perceber que o tipo de letra não varia muito em cada edição, o que muda é o tamanho, se está em negrito ou não e se são utilizadas letras maiúsculas ou minúsculas. Porém, de uma edição para outra é perceptível a mudança na tipologia das letras, sendo a fonte utilizada em 1974, a nosso ver, menos atraente que a fonte utilizada em 2012.

Percebemos, ainda, que a matéria principal da edição de 1974 não se utiliza de diferentes fontes para dar impacto e chamar atenção para o texto, que também apresenta pouco impacto, sendo utilizadas mais imagens do que o próprio texto em si. Já a edição de 2012, além das imagens, utiliza letras em um tamanho grande, maiúsculas e em negrito, o que parece prender melhor a atenção de um possível leitor. Porém, deve-se levar em consideração que a matéria da edição mais antiga trata-se de uma tragédia, e, portanto um assunto mais sério, enquanto, a matéria da edição mais atual fala sobre um escândalo em um reality show, adquirindo assim uma exploração mais gritante.

Sendo que, a matéria que apresenta tal escândalo possui um tamanho do corpo da letra maior e traços mais grossos, o que indica a altura da voz e valorização que se quer dar a notícia, diferentemente, da matéria sobre o incêndio em São Paulo, que utiliza letras com traços finos, representando um tom de voz mais sério ou mais leve. Já a inclinação da letra e a presença do itálico aparecem em ambas como legenda das fotos, ou em caixas de textos paralelos a matéria principal, como na edição de 1974. 
A revista Veja mantém um padrão em suas edições, pois embora tenha mudado ao longo dos anos, como se pode perceber ao folhar duas edições de décadas diferentes, mesmo assim dentro de cada edição, segue certa linearidade quanto ao tipo de letra e organização espacial, visto que os padrões se repetem com constância.

Outro elemento bastante importante e explorado no jornalismo impresso trata-se do fotojornalismo, que é utilizado com frequência em ambas as revistas. Nas duas edições analisadas a fotografia possui uma grande valorização, tendo bastante espaço destinado a esse recurso. As imagens se entrelaçam com o significado do evento, ou ao menos o significado que quer passar exageradamente deste, pois, tanto a edição de 1974 quanto a de 2012 utiliza as imagens que ilustram as matérias principais de forma apelativa.

Enquanto a versão de 1974 busca causar impacto e atrair a atenção do leitor através do uso de imagens fortes, , a edição de 2012 busca atrair os leitores através de fotos que se referem à vida alheia, despertando a curiosidade destes. No caso da edição mais antiga apresentam-se fotos momentos depois de uma tragédia, em que aparecem pessoas mortas, carbonizadas, jogadas pelo chão e sobre o telhado, tratando-se, assim, de uma estratégia de arrebatamento, fisgando o leitor que busca saber notícias e detalhes da tragédia ocorrida. Da mesma forma, a edição mais atual da revista utiliza fotografias de cenas que remetem a realização de sexo no programa $\mathrm{BBB}$, o que instiga a curiosidade e pode sustentar a ideia de que tal ato foi cometido.

Outro motivo que faz com que a fotografia seja tão explorada nas revistas é o fato de que ela serve de prova para mostrar a realidade, tornando-a, dessa forma, inquestionável. No entanto, o fotojornalismo valoriza o flagrante como pode ser percebido na capa e na matéria principal da edição de 1974, onde os fotógrafos conseguiram captar o momento em que ocorria um incêndio em um prédio em São Paulo, assim como momentos depois da tragédia. Já na matéria principal da edição de 2012 aparecem imagens de diferentes momentos que ocorreram durante o programa da Rede Globo, como forma de reafirmar a veracidade do que apresenta a matéria.

Como vimos anteriormente, as mídias impressas como o jornal e a revista mobilizam quatro tipos de estratégias utilizando diferentes tipos de fotos, ou seja, fotos de registro, fotos de síntese, foto de flagrante e foto plástica.

Percebemos o uso da foto de registro na página 3 da edição de 1974 da revista Veja, já que a imagem é meramente ilustrativa, o que condiz com as características descritas da foto de registro, a qual se apresenta como a que mais se aproxima do papel ancorador da fotografia nos textos, utilizada, ainda como uma forma de decorar a página e buscar o olhar do leitor. 
A utilização da foto síntese, por sua vez, foi observada na página 18, também da edição de 1974, onde os corpos estirados pelo chão representam as inúmeras vidas que foram perdidas no incêndio no prédio em São Paulo, pois, como vimos, este tipo de foto é o mais adequado para representar o que é a denominada a "força expressiva" do assunto abordado, ficando evidente para o leitor que a realidade não está sendo mais mostrada de maneira objetiva, mas como um simbolismo do momento ocorrido.

Com relação à utilização da foto de flagrante, que capta o chamado "instante decisivo", tendo, assim, um enorme valor documental e impactante, pois mostra o acontecimento no momento de maior tensão, esta pode ser observada na capa da edição de 1974, em que é feito o registro do momento exato do referido incêndio.

Não encontramos nenhum exemplo que remetesse à utilização da foto plástica em nenhuma das duas edições da revista Veja por nós analisada.

\section{CONSIDERAÇÕES FINAS}

Como vimos, através de nossa análise, a revista Veja mantém um padrão em suas edições, pois, embora tenha sofrido mudanças ao longo dos anos, ela ainda mantém, dentro de cada edição, certa linearidade quanto à constante repetição de seus padrões, através do tipo de letra utilizada nas matérias e organização espacial, por exemplo.

Outro recurso que se repete em ambas a edições da revista é a valorização da fotografia, tendo sido destinado um espaço significativo para esse recurso tanto na edição de 1974, quanto na de 2012. Nessas duas edições da revista, percebemos que as imagens se entrelaçam com o significado do evento, ou ao menos com o significado que se quer passar exageradamente deste, pois, as imagens que ilustram as matérias principais são apresentadas de forma apelativa, como o intuito de chamar a atenção do leitor.

Enquanto a versão de 1974 busca um efeito impactante através da escolha de imagens fortes, captadas momentos depois de uma tragédia, a edição de 2012 busca atrair os leitores através de fotos que se referem à vida alheia, despertando a curiosidade destes.

No que diz respeito ao tema abordado pelas duas edições, percebemos que houve significativa mudança, já que o jornalismo pesado, ligado a temas como política e economia, presentes na edição de 1974, deu espaço a temas mais leves, ligados à vida das pessoas e às celebridades, como vimos na edição de 2012, visando, dessa forma, atingir um maior públicoconsumidor para o produto, elevando, assim, seus índices de vendas e caracterizando um novo ethos do jornalismo no século XXI. 


\section{REFERÊNCIAS}

CHAUÍ, M. S. Simulacro e poder: uma análise da mídia. 1. ed. São Paulo: Editora Fundação Perseu Abramo, 2006.

HERNANDES, Nilton. A mídia e seus truques: o que o jornal, revista, TV, rádio e internet fazem para captar e manter a atenção do público. São Paulo: Contexto, 2006.

VEJA. São Paulo: Editora Abril, edição 283. 6 fev. 1974. Disponível em: $<$ http://veja. abril.com.br/acervodigital/home.aspx> Acesso em: 6 abr. 2013.

VEJA. São Paulo: Editora Abril, edição 2253. 25 jan. 2012. Disponível em: <http://veja. abril.com.br/acervodigital/home.aspx> Acesso em: 6 abr. 2013. 